(From sales figures the incidence of these appears to be lower than 1 in 25,000 .) In some of these patients a history of prior exposure without undue reaction was reported, thus favouring the diagnosis of classic immediate-type allergy-that is, a reaction presumably mediated by reaginic antibodies (mainly IgE). Raised plasma levels of this class of antibody confirm an immediate-type allergy but a normal level does not exclude it. In other patients a similar history was not obtained and thus the reactions appeared to be due to idiosyncrasy, which is defined as a qualitatively abnormal reaction response to the drug - that is, it is not part of its normal pharmacological action and it is not immunologically mediated (Assem, 1967). When reviewing these reports it becomes clear that asthma is a frequent feature in these patients. In some instances premedication (Avery and Evans, 1973) or the use of other drugs may have been involved and recent reports suggest that similar reactions may occur to muscle relaxants (Jerums et al., 1967; Hainsworth and Bingham, 1970).

This report aims to stimulate interest in adverse reactions to intravenous anaesthetics so that the incidence of such reactions to all drugs can be estimated and compared. It is hoped that this publication will encourage reporting of cases both to the Committee on Safety of Medicines and also in response to the request of Dundee and Clarke (1973).

\section{References}

Assem, E. S. K. (1967). Hospital Medicine, 2, 199.

Assem, E. S. K., and McAllen, M. K. (1970). British Medical fournal, 2, 504 Assem, E. S. K., Turner-Warwick, M., Cole, P., and Shaw, K. M. (1971) Clinical Allergy, 1, 353.

Avery, A. F., and Evans, A. (1973). British fournal of Anaesthesia, 45, 301. Clark, M. M., and Cockburn, H. A. (1971). British fournal of Anaesthesia, 43, 185 .

Clarke, R. S. J. (1973). In Intravenous Anaesthesia, ed. J. W. Dundee and G. M. Wyant. Edinburgh, Churchill Livingstone.

Dundee, J. W., and Clarke, R. S. J. (1973). Lancet, 1, 831.

Dundee, J. W., and Wyant, G. M. (1973). In Intravenous Anaesthesia, ed J. W. Dundee and G. M. Wyant. Edinburgh, Churchill Livingstone. Hainsworth, A. M., and Bingham, W. (1970). Anaesthesia, 25, 105.

Jerums, G., Whittingham, S., and Wilson, P. (1967). British fournal of Anaesthesia, 39, 73 .

\title{
Primary Neuropathic Amyloidosis in Three Brothers
}

\author{
A. ZALIN, A. DARBY, S. VAUGHAN, E. B. RAFTERY
}

British Medical fournal, 1974, 1, 65-66

\section{Summary}

Neuropathic primary amyloidosis has not been previously described in an English family. We present the clinical and pathological findings in three brothers with this condition and suggest that they have suffered from that form of the disease described originally by Andrade.

\section{Introduction}

Four clinical patterns of familial neuropathic amyloidosis have been delineated. The first, described by Andrade (1952), originated in Pontugal, and families with this form of the disease but without evidence of Portuguese ancestry have been found in the United States (Shulman and Bartter, 1956), Germany (Delank et al., 1965), and Japan (Araki et al., 1968). The onset is usually in the third or fourth decade with neuropathy starting in the feet. Autonomic disturbance is common and diarrhoea often develops. The course is rapid, with death from cachexia and infection within 4 to 12 years.

The second clinical type was reported by Rukavina et al. (1956) in a family of Swiss origin in Indiana, U.S.A., and was extended to include a large kindred in Maryland (Mahloudji et al., 1969). In this form the onset is in the hands, and manifestations outside the nervous system are rare. The prognosis is relatively poor, patients often dying of unrelated causes. Van Allen et al. (1969) described another pattern in a kindred of English-Soottish-Irish descent in Iowa. Here the onset is in

\footnotetext{
Northwick Park Hospital and Clinical Research Centre, Harrow HA1 3UJ

A. ZALIN, M.B., M.R.C.P., Senior House Physician (Present appointment: Lecturer in Experimental Pathology, Birmingham University)

A. DARBY, M.B., M.R.C.PATH., Senior Registrar, Department of Histopathology

S. VAUGHAN, M.A., B.CHIR., Senior House Officer

E. B. RAFTERY, M.D., M.R.C.P., Consultant Physician
}

the feet, renal involvement with death in uraemia is characteristic, and there is a high incidence of peptic ulceration. Diarrhoea and steatorrhoea are, however, absent. The fourth type was reported by Meretoja (1969) from Finland. The main features are a lattice dystrophy of the cornea and cranial neuropathy. The course is slow and any involvement of peripheral nerves is late and mild.

\section{Case Reports}

CASE 1

A 69-year-old man was admitted to hospital in June 1971 with a history of two years' progressive exertional dyspnoea and recent paroxysmal nocturnal dyspnoea. For 12 months he had suffered gradually-worsening numbness, tingling, and loss of temperature sensation below the knees in both legs. He had also noticed that he was stubbing his toes when going upstairs or when walking on uneven pavements. There had been some mild tingling of the tips of his fingers. The possibility of an autonomic neuropathy was suggested by his complaints of impotence, faintness on rising from a lying position, and alternating constipation and diarrhoea, the latter often being nocturnal.

Both his younger brothers had died (one at another hospital in the region and one in New Zealand) with paralysis and severe wasting. His three sisters were all well; his father died at 84 of heart failure and his mother at 78 with a cerebral infarct.

On examination he had bilateral basal crepitations but no other signs of heart failure. His blood pressure was $130 / 70 \mathrm{~mm} \mathrm{Hg}$ lying, falling to $100 / 60 \mathrm{~mm} \mathrm{Hg}$ standing. He had slight weakness of the intrinsic muscles of the hands, especially the abductor pollicis brevis and interossei. There was also weakness of dorsiflexion of the toes and ankles. The only sensory loss detected in the upper limbs was that of vibration sense up to the metacarpophalangeal joints. In the legs there was pronounced symmetrical sensory loss up to the knees. The perception of deep and superficial pain, temperature, and light touch were all impaired in this area. Vibration and position sense were normal but Romberg's sign was positive. The ankle jerks were absent and there was bilateral thickening of the ulnar and lateral popliteal nerves.

Investigations confirmed disease of the heart and of peripheral and autonomic nerves and showed impairment of renal function. On chest $x$-ray the heart was enlarged and the E.C.G. showed right bundle- 
branch block. He later developed complete heart block with StokesAdams attacks, and an endocardial pacemaker was inserted. The blood urea was $70 \mathrm{mg} / 100 \mathrm{ml}$, and his creatinine clearance was $25 \mathrm{ml} / \mathrm{min}$. His urine was clear of infection and proteinuria was insignificant. On intravenous pyelography the kidneys were small with loss of cortical width. It was thought that renal biopsy was not justified. The conduction rate of both ulnar and lateral popliteal nerves was reduced to 20-35 m/sec (normal 40-50). The autonomic neuropathy was confirmed by monitoring arterial pressure and heart rate during and after the Valsalva manoeuvre. His faecal fat excretion was within normal limits, and the Congo red dye test for amyloid was negative. Biopsy specimens of the sural nerve, rectum, and liver were taken. Small deposits of amyloid, interrupting groups of nerve fibres, were identified in the sural nerve. Amyloid infiltration of vessels was present in a single portal tract in the liver biopsy specimen, and the rectum contained amyloid in the muscularis mucosae, submucosal connective tissue, media of veins, and adventitia of all vessels. A muscle biopsy specimen, obtained when the pacemaker was inserted, showed the same pattern of vascular involvement, a minor degree of sarcolemmal deposition, and infiltration of adipose tissue.

CASE 2

The youngest brother of the first patient became symptomatic at the age of 54 and died four years later. He presented in 1962 with attacks of dizziness and diarrhoea. There was postural hypotension and impairment of light touch sensation in one leg. Two years later sensation was diminished up to the knees and the tendon jerks were absent in both lower limbs. Faecal fat levels were between 3.4 and $10.8 \mathrm{~g}$ daily and xylose absorption was impaired. One year later his arms were involved, with pronounced sensory and motor signs and he had developed cardiomegaly. The E.C.G. showed ischaemic changes and atrial fibrillations. At this stage a diagnosis of amyloid disease was made by histological examination of a nerve biopsy specimen. By this time he was cachectic and he died the following year of his third attack of bronchopneumonia.

At necropsy there was wasting of the upper and lower limbs. The lungs were oedematous, with patchy bronchopneumonic consolidation. The heart was noticeably enlarged, weighing $820 \mathrm{~g}$, with a pale myocardial cut surface. The liver $(1,650 \mathrm{~g})$ and spleen $(240 \mathrm{~g})$ were both slightly enlarged and firm. The wall of the small intestine felt thickened.

Microscopy showed widespread amyloid infiltration. Numerous deposits were seen in sections of femoral nerve and in small nerve branches in skeletal muscle. The heart showed extensive sarcolemmal deposition with some replacement of muscle fibres. Heavy infiltration of the muscle coats of the small and large intestine was present, but skeletal muscle was only slightly involved. Vascular involvement was widespread, mainly affecting the adventitia of arterial and venous branches and the media of veins. Deposition was not seen in the intima and media of arteries. The pulmonary vessels were affected and there was widespread infiltration of alveolar walls. Pancreatic involvement was limited to veins and ducts. Only hepatic artery branches in the portal tracts were infiltrated in the liver, and only subcapsular venules in the adrenal glands. The central nervous system, spleen, and kidney were free of amyloid.

\section{CASE 3}

The third brother also suffered with severe neuropathy and steatorrhoea and died in left ventricular failure at the age of 60 . Necropsy was not performed. At the age of 40 he had a Polya gastrectomy for duodenal ulcer. Twelve years later he underwent bilateral cervical sympathectomy for "circulatory changes" in the hands. At the age of 54 he was found to have steatorrhoea and by then he had impaired sensation in all limbs and knee and ankle jerks were absent. There was no evidence of vitamin $B_{12}$ deficiency. Over the next six years his symptoms worsened despite a gluten-free diet and energetic vitamin replacement. He became cachectic and finally succumbed to a chest infection and left ventricular failure.

The only tissue available for examination was a needle biopsy specimen of liver. Amyloid was not seen in the liver itself but was found in a small fragment of connective tissue included with the biopsy specimen.

\section{Discussion}

The diagnosis of amyloidosis in these three patients is not in doubt. In each case histological confirmation was made by metachromatic staining with methyl violet, fluorescent staining by thioflavin $T$, deep blue staining by the $p$-dimethylaminobenzaldehyde procedure for tryptophan, and positive staining with Congo red dye which showed the characteristic green colour in polarized light. In cases 1 and 2 amyloid was found in peripheral nerve tissue.

Clinically, our cases most resemble those described by Andrade (1952). The Finnish form of the condition is predominantly a cranial neuropathy; Van Allen's patients usually showed renal involvement; and the Rukavina type is relatively benign. Steatorrhoea has not been described in any of these types, but in our cases the rapid course, with diarrhoea, autonomic disturbances, cardiac arrhythmias, and inanition are all features of the Andrade type. There are some minor differences. Congestive cardiac failure is rare in the Andrade form, but was the presenting feature in case 1 . We did not find evidence of sensory dissociation, wheras Andrade stated that thermal and superficial pain sensation was impaired more than light touch. The late onset of symptoms in our patients $(52,54$, and 69 years) is notable. In the original 74 Portuguese patients reported by Andrade symptoms appeared in the third or fourth decades. However, Antunes et al. (1963) reported on 29 Portuguese patients of whom five had onset in the sixth decade and one was aged 66. Our first patient and his relatives were not aware of any Pontuguese ancestry. An English family resembling the present group, also resident in London and with a similar late onset of symptoms, was reported on by $\mathrm{De}$ Bruyn and Stern (1929). The histology of their cases suggested amyloid infiltration of nerves, but special stain could not be used (De Navasquez and Treble, 1938) and so this could not be proved. Unfontunately these patients' records are no longer available and the possibility of a common ancestry cannot be investigated. Thus we believe that we have described the first English family with confirmed neuropathic primary amyloidosis. Though some differences are apparent, we feel that our cases probably come within the Andrade form of the disease.

We thank Dr. P. B. S. Fowler, Dr. J. A. Mallock, Dr. E. Idris Jones, Dr. E. Nassau, Dr. R. Weller, Mr. P. W. D. Corfield, and Mr. J. H. Roberts for allowing us access to clinical and pathological material, and Dr. G. Slavin for advice.

\section{References}

Andrade, C. (1952). Brain, 75, 408

Antunes, L., Ribeiro do Rosario, M., Barros, F., Silva, P., and Coehlo, B. (1963). Etudes sur la Paramyloidose Portugaise a Forme Plunevritique. Suppl. No. 2, p. 12 .

Araki, S., Mawatari, S., Ohta, M., Nakajima, A., Kuroiwa, Y. (1968). Archives of Neurology, 18, 593.

De Bruyn, R. S., and Stern, R. O. (1929). Brain, 52, 84

Delank, H. W., Koch, G., Könn, G., Missmahl, H. P., and Suwelack, K. (1965). Aerztliche Forschung, 19, 407.

De Navasquez, S., and Treble, J. A. (1938). Brain, 61, 116.

Mahloudji, M., et al. (1969). Medicine, 18, 1.

Meretoja, J. (1969). Annals of Clinical Research, 1, 314

Rukavina, J. G et al (1956). Medicine, 35, 239.

Shulman, L. E., Bartter, F. C. (1956). Bulletin of the Fohns Hopkins Hospital, 98,238 .

Van Allen, M. W., Frohlich, J. A., and Davis, J. R. (1969). Neurology, 19, 10. 